\title{
Calculating Skempton constant of aquifer from volume strain and water level response to seismic waves at Changping seismic sta- tion* $^{*}$
}

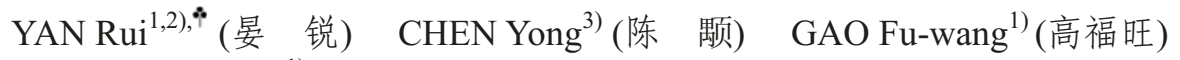 \\ HUANG Fu-qiong ${ }^{1)}$ (黄辅琼) \\ 1) China Earthquake Networks Center, Beijing 100045, China \\ 2) Institute of Earthquake Science, China Earthquake Administration, Beijing 100036, China \\ 3) Institute of Geophysics, China Earthquake Administration, Beijing 100081, China
}

\begin{abstract}
Based on linear poroelastic theory of ideal poroelastic media, we apply the mathematic expression between pore pressure and volume strain for well-aquifer system to analyzing the observed data of water level and volume strain changes aroused by Sumatra $M_{\mathrm{S}} 8.7$ (determined by China Seismic Networks Center) seismic waves at Changping, Beijing, station on December 26, 2004 from both time and frequency domain. The response coefficients of water level fluctuation to volume strain are also calculated when seismic waves were passing through confined aquifer. A method for estimating Skempton constant $B$ is put forward, which provide an approach for understanding of the characteristics of aquifer.
\end{abstract}

Key words: poroelastic theory; Skempton constant; water level; volume strain CLC number: $\mathrm{P} 315.72^{+} 3$ Document code: A

\section{Introduction}

In the previous investigations, many researchers have explained the relationships between water level changes of well-aquifer system and aquifer strain-stress with linear poroelastic theory of ideal poroelastic media (Biot, 1962; Bodvarsson, 1970; Bredehoeft, 1967; Muir-Wood and King, 1993; Kano and Yanagidani, 2006). Many researches indicated that aquifer stress-strain changed arouses pore pressure changes; subsequently the pore pressure changed arouses fluid movement in well-aquifer system, and finally the movements of fluid resulted in the changes of water volume in the borehole. The changes of water volume behave as the well water level changes. According to linear poroelastic theory, the total stress of saturated aquifer is taken together by rock solid framework and pore water. The changes of pore pressure aroused by rock deformation are in proportion to average stress. The proportional coefficient $B$ is called Skempton constant. For seismic

\footnotetext{
* Received 2007-08-21; accepted in revised form 2008-01-04.

Foundation item: National Natural Science Foundation of China (40674024), the 11th Five-Year Program of China Earthquake Administration (2006BAC01B02-03-02) and the Joint Seismological Science Foundation of China (105141).

, Author for correspondence: ray_2005@163.com
} 
wave, the changes of pore pressure in aquifer are aroused by the changes of aquifer stress when the seismic waves are passing through. The changes of total stress are in proportion to the velocity of particulate movement.

The water level fluctuations aroused by seismic waves probably imply some important information about the well-aquifer characteristics. In the recent years, many researchers used the data of water level fluctuation and seismic waves to study hydro characteristics of borehole (Eaton and Takasaki, 1959; Cooper et al, 1965; Bredehoeft et al, 1986; Brodsky et al, 2003; Kano and Yanagidani, 2006). Thereinto, Cooper et al (1965) theoretically deduced amplitude-frequency response characteristics of water level to seismic waves in open borehole, which provides a feasible method for probing into the characteristics of aquifer. Kano and Yanagidani (2006) studied the frequency response range of water level fluctuation to seismic waves with observed data in closed borehole and proposed a kind of method for estimating Skempton constant $B$ with water level fluctuation and seismic wave data.

Based on linear poroelastic theory, we apply the mathematic expression between pore pressure and volume strain for well-aquifer system to analyze the observed data of water level and volume strain changes aroused by Sumatra $M_{\mathrm{S}} 8.7$ (Determined by China Seismic Networks Center) seismic waves at Changping, Beijing, station on December 26, 2004 from both time and frequency domain. The sensitive coefficients of water level to volume strain are calculated. A method for estimating Skempton coefficient is proposed.

\section{Theoretical basis}

\subsection{Constructive relationship of poroelastic media}

The poroelastic theory is a useful truss for studying the coupling effect between pore pressure and fluid diffusion in aquifer system. Biot $(1941,1955)$ firstly put forward stress-strain constructive relationship describing linear elastic and saturated fluid multi-pore elastic media. This relationship gives a kind of general mathematical description for poroelastic media. Afterward, Nur and Byerlee (1971) modified the relationship expression for convenience. Recently, after being modified and expanded by Rice and Cleary (1976), Rudnicki (1986, 1987, 2001), the stress-strain constructive relationship between poroelastic media and rock was formed, which contains pore fluid pressure and heat effect.

$$
\varepsilon_{i j}=\frac{1}{2 G}\left[\sigma_{i j}-\frac{v}{1+v} \sigma_{k k} \delta_{i j}\right]+\frac{\alpha}{3 K} P \delta_{i j}-\alpha_{T}\left(T-T_{0}\right)
$$

In the above theory, besides two usual linear elastic variables, there are two other variables which introduce fluid diffusion, that is, pore pressure $P$ and the fluid mass $m$ in pore media. The characteristic of multi-poroelastic media may be described by the following parameters: diffusive coefficient $C$, Poisson ratio $v$ and $v_{u}$ separately controlling drained and undrained condition, Skempton constant $B$ and shear module $G$.

Then the changes of fluid mass $m$ in standard unit volume can be expressed as

$$
m-m_{0}=\frac{\rho}{G} \frac{3\left(v_{u}-v\right)}{B(1+v)\left(1-v_{u}\right)}\left(\sigma_{k k}+\frac{3}{B} P\right)
$$

Thereinto, $\varepsilon_{i j}$ is the elements of strain tensor, $\sigma_{i j}$ is the elements of stress tensor, $\sigma_{k k}$ is the sum of positive stress, $G$ is shear module of solid media, $K$ is elastic volume module of rock, $v$ is Poisson 
ratio, $\alpha$ is Biot coefficient, $P$ is pore pressure, $\delta_{i j}$ is Kronecker function, $\alpha_{T}$ is linear heat inflation coefficient, $T$ and $T_{0}$ are separately current and original temperature. $m_{0}$ is the mass of fluid under standard state.

To the sudden deformation of aquifer aroused by seismic waves, the instantaneous pore pressure can be explained by poroelastic theory under undrained condition. That is, unit volume fluid mass $m$ is constant. According to expression (2), the relationship between poroelastic pressure and average stress can be expressed as (Piombo A et al, 2005)

$$
P=-B \frac{\sigma_{k k}}{3}
$$

Thereinto, tensile stress is positive. Increase of poroelastic pressure denotes positive. The minus in the above expression denotes that compressive stress corresponds to poroelastic increase.

\subsection{Relationship between poroelastic pressure and volume strain}

When heat effect is ignored, the change of fluid pressure aroused by volume changes of aquifer is (Kano and Yanagidani, 2006)

$$
\begin{gathered}
P=-\frac{2 G B}{3} \frac{1+v_{u}}{1-2 v_{u}} \varepsilon_{k k} \\
\chi=\frac{\varepsilon_{k k}}{P}=-\frac{3}{2 G B} \frac{1-2 v_{u}}{1+v_{u}}
\end{gathered}
$$

According to expression (4), in the saturated fluid multi-poroelastic media aquifer, if $G=3000$ GPa, $B=0.8$ and $v_{u}=0.3$, we can calculate that every micro strain can arouse $52 \mathrm{~cm}$ water column change. That is, when the precision of water level observation is centimeter, the strain of $1.9 \times 10^{-8}$ can be observed. If only increasing the resolution of water level observation, we can observe further small strain changes. So the water level can sensitively respond to the changes of volume strain.

The transmission of seismic waves excited by large earthquakes can arouse volume changes of aquifer system. The changes of volume then result in water level changes of well-aquifer system. The observations of water level and volume strain are replaced in the expression (5). The response coefficient of water column pressure to volume strain can be calculated.

\subsection{Aquifer poroelastic media parameters}

The poroelastic theory of saturated fluid, isotropy media introduces another two parameters based on original ones. One is undrained Poisson ratio and another one is Skempton coefficient $B$. The skempton coefficient is usual constant. It is determined by the rock type and confined condition. It satisfies the condition of $0 \leq B \leq 1$. And $v_{u}$ is limited in the range of $v \leq v_{u} \leq 0.5$. When $B$ and $v_{u}$ value achieve the upper boundary limit, it indicates that the media cannot be compressed. On the contrary, when $B$ and $v_{u}$ value achieve the lower boundary limit, it indicates that the media is easily be compressed. Rice and Cleary (1976), Roeloffs and Rudnicki (1984), Roeloffs (1996) gave $B$ coefficients experimental value. The value is between 0.5 and 0.9 (Table 1).

Table 1 Experimental value of constant $B$

\begin{tabular}{ccccccccccc}
\hline $\begin{array}{c}\text { Rock } \\
\text { type }\end{array}$ & $\begin{array}{c}\text { Ruhr } \\
\text { Sandstone }\end{array}$ & $\begin{array}{c}\text { Berea } \\
\text { Sandstone }\end{array}$ & $\begin{array}{c}\text { Weber } \\
\text { Sandstone }\end{array}$ & $\begin{array}{c}\text { Charcoal } \\
\text { granite }\end{array}$ & $\begin{array}{c}\text { Westerly } \\
\text { granite }\end{array}$ & $\begin{array}{c}\text { Tennessee } \\
\text { marble }\end{array}$ & Cement & $\begin{array}{c}\text { Compaction } \\
\text { sand }\end{array}$ & $\begin{array}{c}\text { Loose } \\
\text { sand }\end{array}$ & $\begin{array}{c}\text { Clay } \\
\text { Band }\end{array}$ \\
\hline$B$ & 0.88 & 0.62 & 0.73 & 0.55 & 0.85 & 0.51 & 0.58 & 0.99 & 0.998 & 1 \\
\hline
\end{tabular}




\section{Changping observation station}

Changping (Dong Sanqi) station locates in Changping District, Beijing City. The altitude is $38.8 \mathrm{~m}$. The station belongs to the cross area of Yanshan structure belt and New Cathaysian structure belt of North China. The regional structure locates in Laiguangying anticline at Beijing sunken area. The site locates at the cross area of NE Huangzhuang-Gaoliying fault, WNW Nankou-Sunhe fault and NNE Babaoshan fault. The surface is covered by Quaternary system sediment layer. The structure activities are comprehensive in this area and it is a sensitive site for earthquake precursor observation (FANG, 1998).

Changping volume strain station is a substation of the Sacks comprehensive volume strain observation network at Capital Circle Area. The depth of borehole for the volume strain gauge is 285 $\mathrm{m}$. The stratum above $198 \mathrm{~m}$ at the site is Quaternary system loosen sediments layer. It is made up of clay, sand clay and thin gravel. The lower stratum is Sinian system resembling limestone. The instrument in the borehole is Sacks-Eyertson drilled strain gauge. The sensitivity is set as $10^{-11} / \mathrm{mV}$, the measurement accuracy is $10^{-9} / \mathrm{mV}$. The data can record clearly Earth tides and are stable.

The observations of water level and volume strain are in the same borehole at Changping station. The sensor of volume strain is located at the bottom of the well. The SWY-1 style water level gauge is installed on September, 2001 and the sensor is located at several meters below water surface. This well is made up of two aquifers. The upper part above $198 \mathrm{~m}$ belongs to pore water. It is supplied mostly by precipitation and surface water infiltration. The lower part is cranny karst water of carbonate rock. The cranny and water are rich. The water is confined. According to the construction design, the water level changes in this well belong to the lower part cranny confined water. The tidal records are clear under normal condition. The station is reinstalled digital instruments on September 2001. Volume strain and water level observations are all digitally automatic record. Minute sample and automatically transmitting data are realized at this station ${ }^{\circledR}$ (WU et al, 2006; ZHANG, 2005).

\section{Response of water level to seismic waves}

The intensive Sumatra $M_{\mathrm{S}} 8.7$ earthquake $\left(95.9^{\circ} \mathrm{E}, 3.9^{\circ} \mathrm{N}\right)$ occurred on December 26,2004 in Indonesia Island. This earthquake aroused great change of water level and volume strain in most area of Chinese mainland. Figure 1 is the water level and volume strain response to the Sumatra earthquake at Changping station. The distance from the epicenter to Changping earthquake station is about $4500 \mathrm{~km}$. The figure clearly indicates that the earthquake aroused great fluctuation of water level and volume strain. The fluctuations continue for several hours. The greatest amplitude of water level is $102.6 \mathrm{~mm}$. The greatest amplitude of volume strain is $1.922 \times 10^{-7}$.

In order to clearly understand the relationship between water level and volume strain, wavelet decomposition of $\mathrm{db} 2$ were used to analyze water level and volume strain in detail. The wavelet decomposes water level and volume strain into several parts of detailed data at different frequency band (Figure 2). From Figure 2, we can see that there are some comparability between water level and volume strain at different frequency band. This is in accordance with the results of linear poroelastic theory. That is, the water level fluctuation is in proportion to volume strain changes.

\footnotetext{
(1) ZHANG Ling-kong. 2005. Volume strain observation report of Indonesia earthquake occurred in 2004 and 2005 at Dong Sanqi station [G]//Crust Structure and Crust Stress, (1): 18-19 (in Chinese).
} 
In order to testify the relationship between water level and volume strain, water level and volume strain data on December 26, 2004 are removed linear trend and make coherent function analysis (Figure 3). Figure 3 indicated that water level was coherent with volume strain at certain frequency. The theory and observation facts indicate that water level and volume strain at Chang-
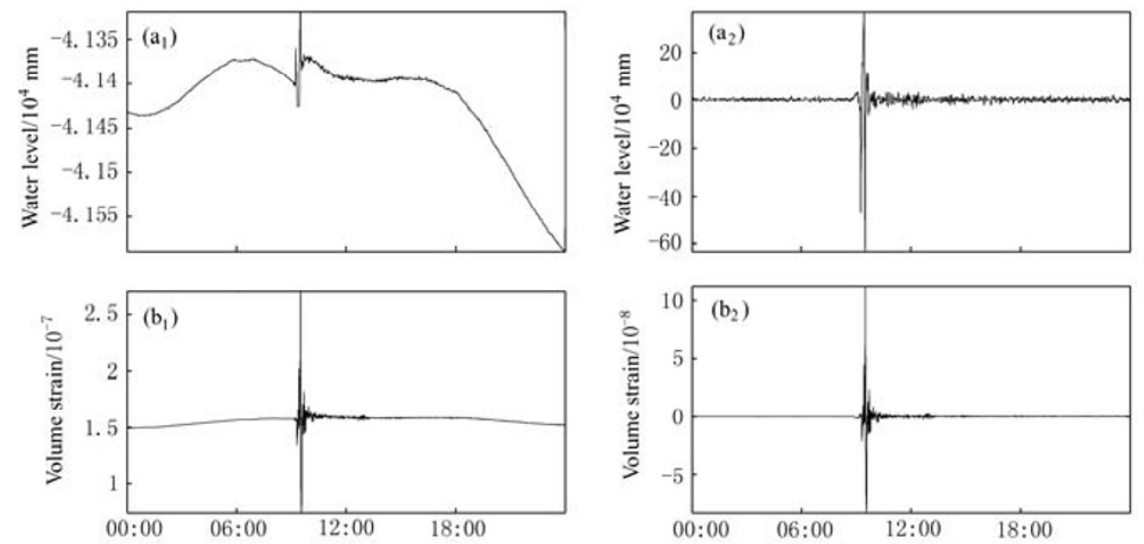

Figure 1 Water level and volume strain response to Sumatra $M \mathrm{~s} 8.7$ earthquake at Changping station on December 26, 2004

$\left(a_{1}\right)$ Raw minute data of water level; $\left(a_{2}\right)$ water level after removing linear trend; $\left(b_{1}\right)$ raw minute data of volume strain; $\left(b_{2}\right)$ volume strain after removing linear trend
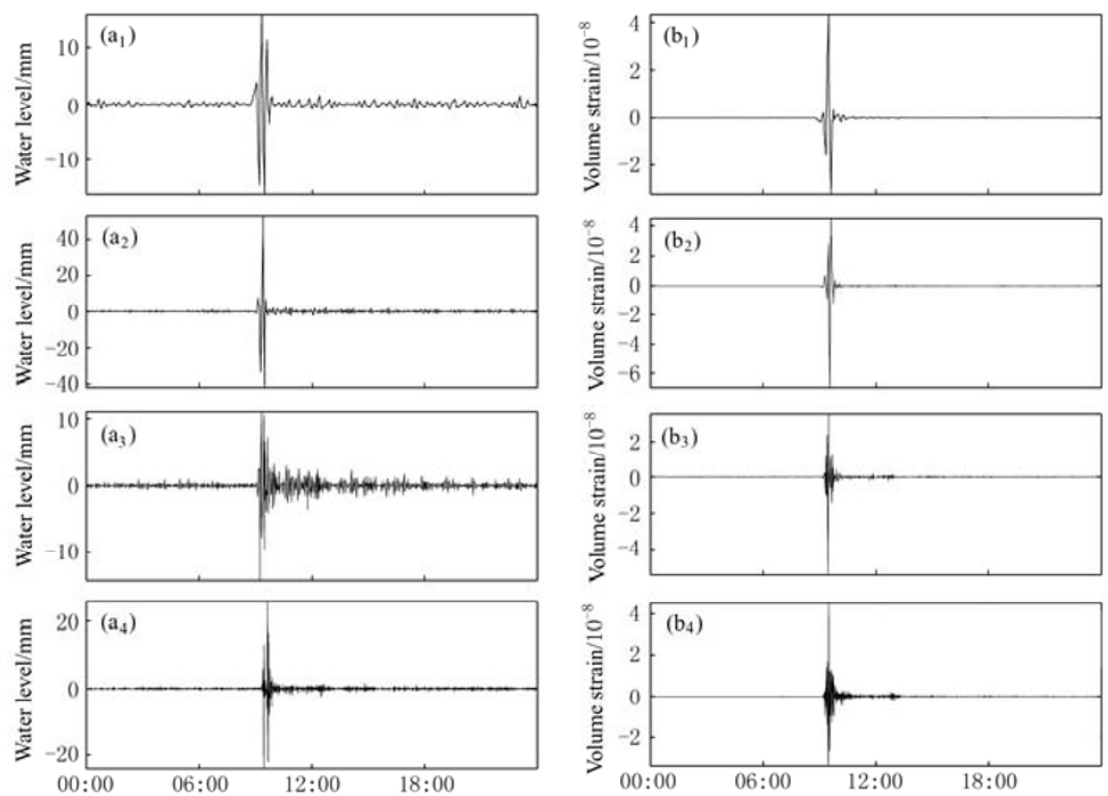

Figure $2 \mathrm{db} 2$ wavelet decompositions of water level and volume strain data at Changping station $\left(a_{1}\right)$ The fourth layer wavelet decomposition result of water level; $\left(b_{1}\right)$ The fourth layer wavelet decomposition result of volume strain; $\left(a_{2}\right)$ The third layer wavelet decomposition result of water level; $\left(b_{2}\right)$ The third layer wavelet decomposition result of volume strain; $\left(\mathrm{a}_{3}\right)$ The second layer wavelet decomposition result of water level; $\left(b_{3}\right)$ The second layer wavelet decomposition result of volume strain; $\left(a_{4}\right)$ The first layer wavelet decomposition result of water level; $\left(\mathrm{b}_{4}\right)$ The first layer wavelet decomposition result of volume strain 
ping station have some correlation. So water level and volume strain can be regard as zero order linear system to dispose.

In order to get the sensitive coefficient of water level to volume strain, water level and volume strain aroused by earthquake are fitted by least square linear model (Figure 4). The slope of the fitted line is the sensitive coefficient $\chi$ of water level to volume strain. This coefficient is equal to $1.875 \times 10^{-9}$ for this station. According to equation (5), the Skempton constant $B$ can be estimated with sensitive coefficient. The estimated value of Skempton constant is equal to 0.804 at Changping station.

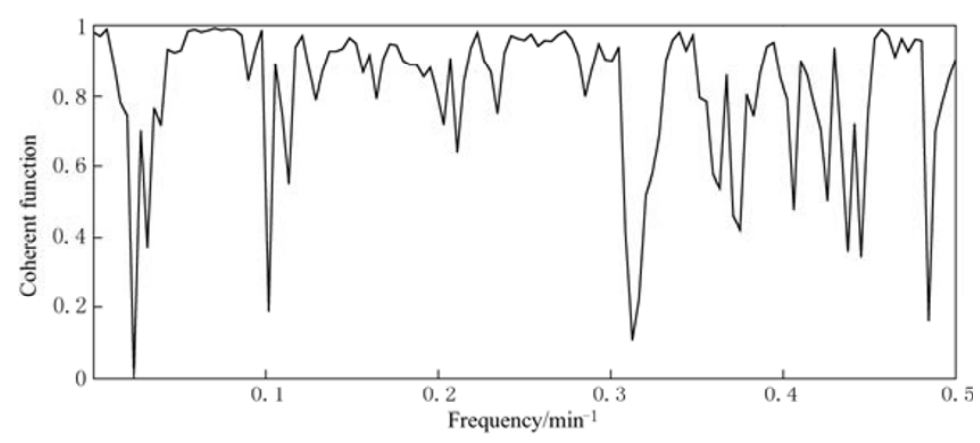

Figure 3 Coherency function estimation between water level and volume strain

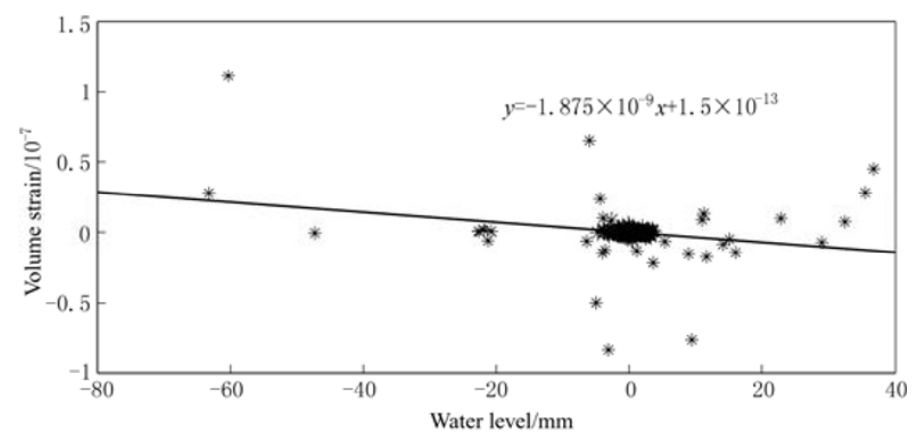

Figure 4 Amplitude ratio of water level to volume strain changes

In order to know the frequency characteristics of water level and volume strain fluctuation, the frequency spectrum analysis of water level and volume strain before and after earthquake are separately made. Because of the sample rate of observed data is minute sample, the Nyquist frequency is $0.5 \mathrm{~min}^{-1}$. Figures $5 \mathrm{a}$ and $5 \mathrm{~b}$ are separately frequency spectrum of water level and volume strain. Dotted line is the amplitude spectrum of 10 hours before the earthquake. It illustrates the noise level of observation. The real line is the amplitude spectrum of 10 hours after the earthquake. The spectrums of water level and volume strain have certain comparability and great fluctuation occurs at high frequency. The spectrum analysis indicated that the response range of water level and volume strain to seismic waves is from 0.02 to $0.2 \mathrm{~min}^{-1}$. The signal noise ratio is lack beyond this frequency range. The amplitude ratio of water level to volume strain is flat from 0.02 to $0.2 \mathrm{~min}^{-1}$. The ratio is about $2.213 \times 10^{-9}$. That is, the sensitive coefficient $\chi \approx 2.213 \times 10^{-9}$. The standard error is $0.4372 \times 10^{-9}$. The average of Skempton constant $B$ is equal to 0.7316 . Standard 
error is 0.1373 . This value is in accordance with the value calculated in time domain.

\section{Discussion and conclusions}

Under certain condition, in well-aquifer system water level fluctuation aroused by seismic waves can be explained by linear poroelastic theory of multi-poroelastic media. Supposed that the
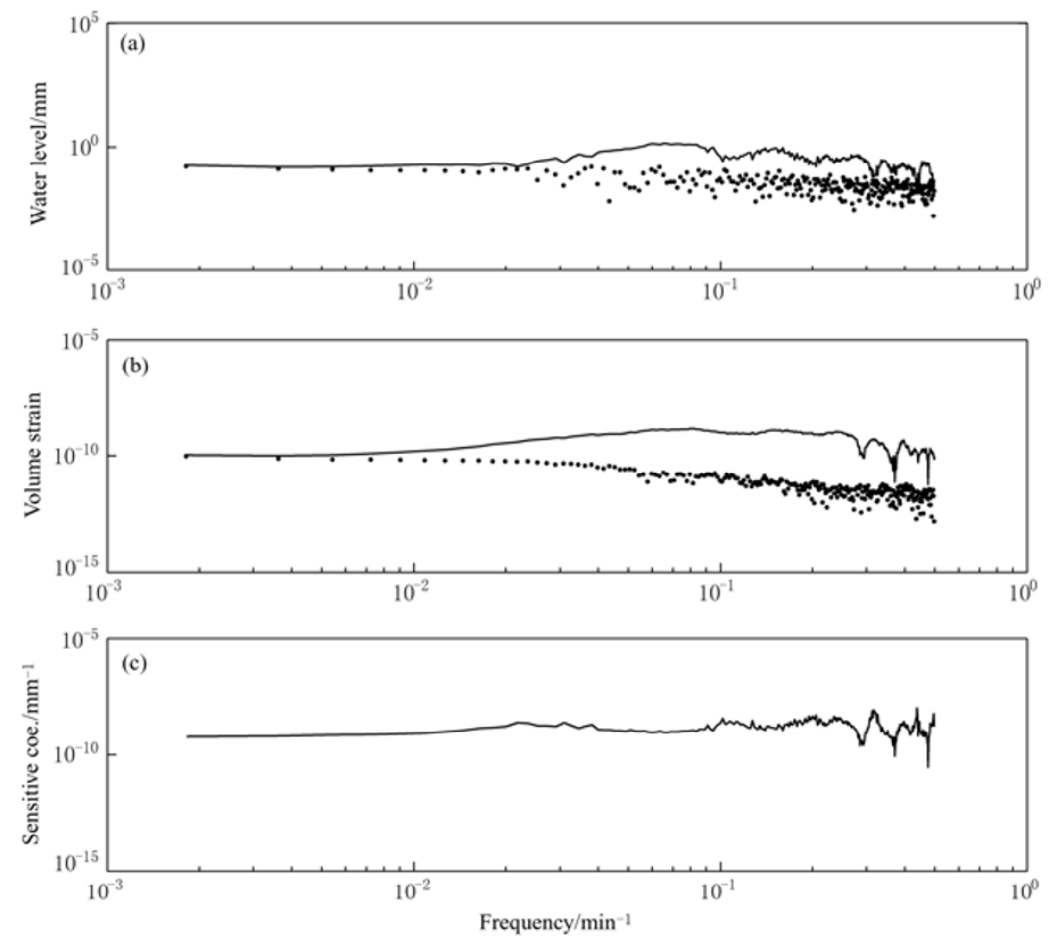

Figure 5 Frequency-spectrum analysis of water level and volume strain at Changping station

(a) Frequency-spectrum of water level, dots are amplitude spectrum of 10 hours before earthquake. Solid curve is amplitude spectrum of 10 hours after earthquake; (b) Frequency-spectrum of volume strain; dots are amplitude spectrum of 10 hours before earthquake. Solid curve is amplitude spectrum of 10 hours after earthquake; (c) Amplitude ratio of volume strain to water level

aquifer system can be regard as ideal poroelastic media, the sensitive coefficient $\chi$ in equation (5) can be calculated by the observed data of water level and volume strain. This value reflects the sensitivity of water level to volume strain changes. The Skempton constant $B$ which reflects the characteristics of aquifer can be further calculated.

In well-aquifer system water level and volume strain observed data aroused by seismic waves are used to estimate sensitive coefficient and Skempton constant $B$ in this paper. This method provides an approach for understanding the characteristics of aquifer, but there are some deficiencies and need be further improved.

1) Equation (5) is deduced under undrained condition, but well-aquifer system is open in itself. Even if the aquifer satisfies undrained condition, the borehole connected with aquifer makes up of drained passage in itself. The pore pressure changes of aquifer make water flow into or out borehole to produce the water level changes. Because of the water flow between aquifer and borehole, the sensitivity will fall and produce phase lags. This is called storability. 
2) The flow of water cannot be ignored under most conditions. For example, when the Sumatra $M_{\mathrm{S}} 8.7$ (determined by China Seismic Networks Center) earthquake occurs, the water of Chaigan well in Guangdong Province erupted about $60 \mathrm{~m}$ high above the Earth surface. Such case cannot be explained by the method supplied in this paper. Generally, the changes of fluid pressure are smaller than the value deduced by equation (4). The calculated value with equation (5) and observed data of water level and volume strain is usually the lower limit.

3) If the strain rate is too low or there is some aperture in the confined aquifer clapboard, the water will flow vertically to the water table. This will make the response of water level and volume strain to seismic different. Under such condition, the calculating precision will be affected.

4) The major period of seismic waves is 10 to $20 \mathrm{~s}$ and the period of surface waves is about $40 \mathrm{~s}$. But the sample rate of water level and volume strain is one point per minute. Under such condition, the record of water level and volume strain cannot completely record the real seismic process. So the calculated results exists certain limits

Acknowledgements We sincerely thank Professor CHE Yong-tai for the valuable suggestions.

\section{References}

Biot M A. 1941. General theory of three-dimensional consolidation [J]. Appl Phys, 12(2): 155-164.

Biot M A. 1955. Theory of elasticity and consolidation for a porous anisortopic solid [J]. J Appl Phys, 26(2): 182-185.

Biot M A. 1962. Mechanics of deformation and acoustic propagation in porous media [J]. J Appl Phys, 33(4): $1482-1498$.

Bodvarsson G. 1970. Confined fluids as strain meters [J]. J Geophys Res, 75(14): 2711-2 718.

Bredehoeft J D, Roeloffs E A, Riley F. 1986. Water wells as strain-meters at Parkfield [J]. Eos, Trans, Amer Geophys Union, 67(16): 242.

Bredehoeft J D. 1967. Response of well-aquifer systems to Earth tides [J]. J Geophys Res, 72(12): 3 075-3 087.

Brodsky E E, Roeloffs E, Woodcock M, et al. 2003. A mechanism for sustained groundwater pressure changes induced by distant earthquakes [J]. J Geophys Res, 108(B8): 2930-2940.

Cooper H H, Bredehoeft J D, Papadopulos I S, et al. 1965. The response of well-aquifer systems to seismic waves [J]. J Geophys Res, 70(16): 3915-3926.

Eaton J P and Takasaki K J. 1959. Seismological interpretation of earthquake-induced water-level fluctuations in wells [J]. Bull Seism Soc Amer, 49(3): 227-245.

FANG Xiao-xiang. 1998. Study on the Site of Earthquake Precursor Observation Station at Beijing Area [M]. Beijing: Seismological Press: 20-21 (in Chinese).

Kano Y and Yanagidani T. 2006. Broadband hydroseismograms observed by closed borehole wells in the Kamioka mine, Central Japan: Response of pore pressure to seismic waves from 0.05 to $2 \mathrm{~Hz}$ [J]. J Geophys Res, 111(B03410): 1-11.

Muir-Wood R and King G C P. 1993. Hydrological signatures of earthquake strain [J]. J Geophys Res, 98(B12): 22 035-22 068.

Nur A and Byerlee J D. 1971. An exact effective stress law for elastic deformation of rock with fluids [J]. J Geophys Res, 76(26): 6414-6419.

Piombo A, Martinelli G, Dragoni M. 2005. Post-seismic fluid flow and Coulomb stress changes in a poroelastic medium [J]. Geophy J Int, 162(2): 507-515.

Rice J R and Cleary M P. 1976. Some basic stress diffusion solutions for fluid-saturated elastic porous media with compressible constituents [J]. Rev Geophys, 14: 227-241.

Roeloffs E. 1996. Persistent water-level changes caused by seismic waves; evaluation of non-poroelastic mechanisms [C]. Eos, Trans Amer Geophys Union, AGU 1996 fall meeting, 77(Suppl.): 228.

Roeloffs E and Rudnicki J W. 1984. Coupled deformation-diffusion effects on water-level changes due to propagating creep events [J]. Pure Appl Geophys, 122(2-4): 560-582.

Rudnicki J W. 1986. Slip on an impermeable fault in a fluid-saturated rock mass [G]//Das S, Boatwright J, Scholz C H. Earthquake Source Mechanics, Geophysical Monograph Series. Washington: American Geophysical Union, 37: 81-89.

Rudnicki J W. 1987. Plane strain dislocation in linear elastic diffusive solids [J]. ASME J Appl Mech, 109: 545-552.

Rudnicki J W. 2001. Coupled deformation-diffusion effects in the mechanics of faulting and failure of geomaterials [J]. ASME Appl Mech Rev, 54(6): 483-502.

WU Pei-zhi, XU Ping, XING Cheng-qi, et al. 2006. Observation of GPS body-strain and underground-water in Dongsanqi Station [J]. Earthquake, 26(3): 131-135 (in Chinese). 